DOI 10.37882/2223-2982.2021.07.21

\title{
ИССЛЕДОВАНИЕ ЛИНГВИСТИЧЕСКОГО ЛАНДШАФТА И ЕГО АНАЛИЗ В РОССИИ И КИТАЕ
}

\section{LINGUISTIC LANDSCAPE RESEARCH AND IT'S ANALYSES IN RUSSIA AND CHINA}

Liu Jingpeng

Summary: Linguistic landscape is a new area of research in sociolinguistics and applied linguistics. The research of linguistic landscape had begun in the 70-80s of the XX century, it laid the foundations for the process of studying bilingual or multilingual phenomena. Currently, the development of Russian-Chinese relations has reached its peak, humanitarian cooperation and cultural exchange between Russia and China are being strengthened. In this process, the role of the linguistic landscape in the combination of Russian and Chinese is very primising. The article discusses some aspects of the study of linguistic landscape in Russia and China, and analyzes errors in the translation from Chinese into Russian and from Russian into Chinese.

Keywords: linguistic landscape, sign-boards, Russian language, Chinese language, translation error.

\section{Аингвистический ^андшафт: обшие положения}

$\Pi$ олучив свое развитие в 70-80-ые годы XX века, изучение лингвистического ландшафта являлось объектом пристального внимания специалистов в области социолингвистики, социологии, семиологии и психологии на протяжении предыдущих лет [1]. Впервые понятие «лингвистический ландшафт» (Linguistic Landscape) было использовано в 1997 году канадскими учеными Р. Лоундри и Р. Борхис для описания бытования языков в городском пространстве. В своей работе «Лингвистический ландшафт и этнолингвистическая жизненность. Эмпирическое исследование» они определяют лингвистический ландшафт как «языки, которые появляются на общественных вывесках, рекламных щитах, в названиях улиц, в названиях местности, на вывесках магазинов и зданий органов власти в определенной местности, регионе или городской агломерации» [2]. Американские ученые Рон Сколлон и Сюзан Вон Сколлон в работе «Discourses in Place: Language in the Material World» анализируют тексты наружных вывесок в городах стран Азии, Европы и США, изучают смысловые системы слов в материальном и реальном мирах, а также вводят понятие географической семиологии (Geosemiotics). Gorter представляет языковой ландшафт как новый путь изучения многоязычия (multilingualism), рассматривая местный языковый ландшафт одновременно в разрезе влияния его языковой семьи и глобальных языков, в осо-

\author{
Лю Цзинпэн \\ Аспирант, МГУ имени М.В. Ломоносова \\ liudabao7777@gmail.com
}

Аннотация: Лингвистический ландшафт представляет собой новое направление исследования в социолингвистике и прикладной лингвистике. Начав свое развитие в 70-80-ые годы XX века, оно заложило основы процесса изучения двуязычных или многоязычных явлений. В настоящее время развитие российско-китайских отношений достигло своего пика, укрепляются гуманитарное сотрудничество и культурный обмен между Россией и Китаем. В данном контексте роль лингвистического ландшафта в комбинации русского и китайского языков представляет особый интерес для изучения. В статье рассматриваются некоторые аспекты исследования лингвистического ландшафта в России и Китае, а также проводится анализ ошибок в контексте лингвистического ландшафта российского и китайского пространств.

Ключевые слова: лингвистический ландшафт, вывески, русский язык, китайский язык, переводческие ошибки.

бенности английского.

В России изучением явления присутствия языка в городском пространстве занимаются такие исследователи как Абрамова Е.И., Кирилина А.В., Подберезкина Л.В., Купцова Г.И., Пешкова Н.П. и другие. Авторы исследуют процессы, оказывающие влияние на формирование, функционирование и распространение языка в городской среде, а также занимаются изучением проблем моделирования, развития и влияния на реципиентов городского лингвистического ландшафта. Дубковой О.В. и Захаровой-Саровской М.В. рассматривается вариативность моделей словосложения, используемых при образовании современных китайских эргонимов. Шипановская Л.М. изучает вывески на русском языке как фрагмент коммуникативного пространства приграничных китайских городов. Анализом русскоязычных вывесок в лингвокультурном пространстве китайского города с точки зрения наличия лингвистических ошибок также занимаются такие исследователи как Харченко Е.В. совместно с Мань Шу [3].

В Китае исследованием лингвистического ландшафта занимаются такие ученые, как Бао Сюе, Цзэн Лису, Чэнь Цзие, Чэнь Шэнбай, Цай Сыин, Гао Шань, Ли Лишен, Шан Гуовен, Чжао Шоухуэй, Се Сяомэн, Лю Лифэнь и другие. Большинство китайских публикаций о языке общественных знаков сконцентрировано на теме перевода на ан- 
глийский язык (Ло Сюаньмин, Ли Шиванг, Ян Юнхэ, Чжао Сян). Тян Фэйян и Чжан Вэйцзя на примере двуязычных уличных указателей, расположенных на пекинской улице Сюэюань, показывают, что проблематика изучения языка общественных знаков (公示语) гораздо шире только вопроса перевода на английский язык, поскольку языковые символы отражают множество социальных и культурных проблем. Изучением различных социально-политических и идеологических факторов, скрытых за языковыми проблемами также занимаются такие китайские ученые, как Ли И, Сунь Ляньхуа и Гу Юэ, Ся На и другие. Сюй Хунган и Жэнь Янь на примере используемой на указательных знаках в древнем городе Лицзян на реке Шу последовательности письменности народности наси дунба, английского, и китайского языков показывают, что превратившемуся в связи с расцветом туристической отрасли в коммерциализированный символ языку дунба, по факту не достает информативной функции, поддерживаемой жизненным потенциалом языка. Указанные выше эмпирические исследования отражают языковые контакты и изменения в этих процессах в определенных регионах, обусловленные потенциалом языков национальных меньшинств, сложностью исторического процесса и культурным многообразием региона[4]. Проблематика коммуникативного пространства приграничных китайских городов подвергалась анализу в работах Цзян Ин [Цзян 2016], Мань Шу [Мань 2018].

При наблюдаемом росте научного интереса к проблематике лингвистического ландшафта, обусловленного воздействием процессов глобализации на жизнь современного общества, следует отметить, что в настоящее время это относительно новая лингвистическая дисциплина, и ее теоретические установки находятся в процессе становления [5]. Существует не только множество синонимов лингвистического ландшафта, таких как языковой ландшафт, городской текст, лингвогеография и так далее, но и определений, представленных разными учеными. В целом, понятие «лингвистический ландшафт» можно понимать как языковые средства, которые создают визуальную окружающую среду. Т.е. лингвистический ландшафт - это область изучения и исследования различных языковых единиц, которые выполняют определенные функции и обладают конкретными задачами в городской среде, междисциплинарный метод, так и непосредственно совокупность различных текстов и наименований, представленность языков в общественном пространстве. При этом важно понимать, что исследование лингвистического ландшафта фокусирует внимание не на содержании вывесок, а на той социально-языковой действительности, которую отражают языки вывесок [6].

Методология исследования ^ингвистического ^анАшафта

Как уже было отмечено выше, лингвистический ландшафт- это относительно новая лингвистическая дисциплина, теоретические установки которой все еще находятся в стадии формирования. Обзор литературы показывает, что степень изученности лингвистического ландшафта в разных странах отличается. Например, западные ученые в течение нескольких десятилетий анализируют языковой ландшафт с точки зрения различных подходов, а именно политического, социального, экономического, этнического и т.д. в России изучением языка В контексте полиэтнического городского пространства стали заниматься относительно недавно [7]. В Китае неизбежным направлением проведения эмпирических исследований лингвистического ландшафта считается количественный и качественный методы исследований [4].

Для изучения лингвистического ландшафта характерны подходы, применяемые в рамках исследований в области социолингвистики, этнолингвистической витальности, семиотики, языкового менеджмента и т.д. Также, поскольку объектом изучения лингвистического ландшафта являются вывески, веб-сайты и реклама, для проверки гипотез зачастую используется предполагающий применение количественных и качественных методик метод триангуляции [7]. Для написания данной статьи нами также были использованы указанные методики. Сбор материала в таком случае осуществляется методом фотографирования, после чего данные классифицируют и анализируют. Классификация осуществлялась по принципу соотнесения вывесок к двум возможным типам: это вывески, имеющие официальный характер, такие как таблички с названиями улиц, памятников, и зачастую отражающие правительственную позицию или популярное направление политики, а также частные вывески целью создания которых является использование в целях коммерции или информирования. Примером частных вывесок могут служить вывески с названиями публичных заведений, плакаты и т.д.

\section{Исследование ^ингвистического ^андшафта с точки зрения перево $а$}

Язык вывесок, размещенных в публичном пространстве городской среды, является отражением ее социально-языковой действительности. Языковой ландшафт города не только демонстрирует применение языка в регионе, но и отражает степень открытости города, его экономическую активность и уровень жизни, более того, раскрывает политическую ориентацию властей и проводимой ими политики, отражает положение и статус языков [8], и по этой причине является одной из передовых тем для исследований в области социолингвистики.

Зародившийся в дву- и многоязычных городах и регионах, метод лингвистического ландшафта в настоящее время рассматривается также и с точки зрения изменившихся условий функционирования языка, вызванных 
глобализацией. Наблюдаемый процесс сближения регионов, маркерами которого можно назвать рост туристического потока, количества иностранных студентов и иностранной рабочей силы, также оказывает свое влияние на языковую среду в общественной сфере.

Учитывая тот факт, что нейтральная коммуникация и нейтральная передача информации от автора адресату невозможна, т.е. реципиент играет активную роль в процессе восприятия информации, интерпретируя ее, визуализируя и создавая ассоциации [9], при том, что целью автора воздействия обычно является побуждение адресата к посткоммуникативной деятельности [10], роль правильного, корректного перевода с языка автора воздействия на язык реципиента в процессе применения лингвистического ландшафта сложно переоценить. Однако, не стоит также упускать из внимания, что на протяжении всей своей истории перевод, нередко определяемый как искусство - искусство речевого преобразования, искусство медиации, искусство принятия решения в обстановке неопределенности - предполагает не только технологическое мастерство, но и креативность, даже хитрость, ловкость и сообразительность, а также социальную и психологическую адаптивность, которые также могут позволить достичь нужного автору текста эффекта.

Вместе с тем следует отметить, что Общественный статус перевода ставит его в зависимость от целого ряда социальных факторов. Социальный статус коммуникантов, в том числе и самого переводчика, общественная значимость каждого перевода, условия коммуникации и многие другие факторы обусловливают как протекание самого процесса перевода, так и свойства создаваемого переводчиком «продукта».

Лингвистический ландшафт и его применение начинаются с вопроса «Что есть перевод?». Как отмечает Гарбовский Н.К.: «Перевод - это вид языкового посредничества, при котором на другом языке создается текст, предназначенный для полноправной замены оригинала, в качестве коммуникативно равнозначного последнему» [11]. Перевод, по сути, представляет собой операцию по расшифровке смыслов, извлеченных из сообщения, созданного средствами одного естественного языка, и воспроизведения их в сообщении, создаваемом средствами другого естественного языка. Также следует отметить, что перевод всегда предполагает оперирование определенными знаковыми системами, т.е. имеет знаковую, семиотическую сущность. Он может осуществляться как между разными семиотическими системами, так и между разными вариантами одной и той же семиотической системы.

Целью любого перевода является наиболее близкое ознакомление реципиента с данным текстом, для определения точности которого не так давно в теории перевода было введено понятие «эквивалентность». «Понятие эквивалентности, - утверждает В.Н. Комиссаров, - раскрывает важнейшую особенность перевода и является одним из центральных понятий современного переводоведения». Однако следует обратить внимание на относительность эквивалентности, что для теории перевода имеет принципиальное значение. Эквивалентность предполагает взаимозаменяемость сравниваемых объектов, но взаимозаменяемость не абсолютную, а возможную только в каком-либо отношении.

Применительно лингвистического ландшафта точность перевода важна ввиду того, что адресатами в данном случае выступают как иностранцы, которые работают, учатся, живут и путешествуют заграницей, так изучающие данный иностранный язык местные жители. Надписи, расположенные в общественных местах чаще всего не предназначены для обучения иностранному языку, однако зачастую служат одним из источников для его изучения ввиду так называемого случайного запоминания. Носитель языка без труда отметит наличие различного рода переводческих ошибок в тексте вывесок, в то время как изучающий иностранный язык будет убежден в правильности текста на иностранном языке, присутствующем на таких надписях.

\section{Анализ ^ингвистического ^анАшафта в комбинашии русского и китайского языков}

В настоящее время российско-китайские отношения находятся на пике своего развития. Набирает обороты и гуманитарное сотрудничество между странами. В этом процессе российско-китайский лингвистический ландшафт приобретает особое значение. По мере укрепления российско-китайского сотрудничества растет количество китайских студентов, обучающихся в России, и количество российских студентов, обучающихся в Китае, увеличивается туристический поток между странами, растет количество российской иностранной рабочей силы из России и Китая, все больше людей испытывают интерес к изучению русского и китайского языков, и, как следствие, в лингвистических ландшафтах обеих стран появляется все больше текстов на иностранных языках.

Несмотря на то, что в приграничных городах России и Китая двуязычные вывески получили распространение уже на протяжении довольно длительного времени [13], распространение китайского языка в лингвистическом ландшафте средней полосы и европейской части России - явление относительно новое. В России изначально более распространены двуязычные вывески и указательные знаки на русском и английском языках. Однако начиная с 2018 года, т.е. после проведения Чемпионата мира по футболу, в России повсеместно стали появляться двуязычные вывески и указатели на русском и китай- 
ском языках. Сейчас в России отмечается китайский бум, что, на наш взгляд, в будущем, несомненно, отразится на масштабе присутствия китайского языка в лингвистическом ландшафте российских городов и других населенных пунктов.

В Китае двуязычные вывески на русском и китайском языках появились значительно раньше, чем в России. В основном это были приграничные города, а также российские города - побратимы. Хорошим примером присутствия русского языка в контексте китайского города могут также служить зоны приграничного экономического сотрудничества, например, город Маньчжурия, который в 1992 году получил статус открытого приграничного города, и где в том же году официальным письмом Госсовета было утверждено создание российскокитайской приграничной торговой зоны. В настоящее время присутствие русского языка в лингвистическом ландшафте китайского города также наблюдается и по некоторым популярным среди российских туристов направлениям, таким как Санья [6], Бэйдайхэ и т.д.

Однако, несмотря на стремительное распространение русского и китайского языков на территории России и Китая, множество надписей на вывесках содержат ошибки. Согласно некоторым статистическим данным, такие надписи можно разделить на две функциональные группы: 1. Указатели; 2. Напоминания или запреты.

К указателям можно отнести следующие примеры:

- Запасный выход. 安全出口;

- Кабинет №10.10号办公室№10.

Примеры группы напоминаний и запретов. Напоминания:

- Нажмите сюда. 请按这里;

- Закройте дверь! 请关门;

- 救生衣在中间扶手下Спасательный жилет под перилами;

- При аварии провернуть ручки по стрелке! 紧急情

\section{况下按箭头方向扭动把手.}

Примеры запретов:

- Не трони! 不要触摸!

- Не входит! Идет государственный экзамен. 不要进入! 正在国考。

- 禁止入内 Входить запрещен

- 禁止靠近 Близко не подходить

Исследователи выделяют различные классификации переводческих ошибок: ошибки по этапам перевода, ошибки с точки зрения языка и логичности, ошибки по степени дезинформирующего воздействия, ошибки по принципу мотивированности / немотивированности, ошибки с учётом причин их возникновения, ошибки с точки зрения функционализма теории перевода. Применительно перевода вывесок с русского языка на китайский и с китайского на русский, по результатам проведенных исследований лингвистического ландшафта в комбинации русского и китайского языков многие специалисты отмечают, что наиболее часто встречающимися ошибками являются ошибки с точки зрения языка и логичности, а именно следующие три типа: орфографические, грамматические и лексические ошибки, которые можно отнести к ошибкам с точки зрения языка и логичности.

Далее мы хотели бы проанализировать вышеуказанные четыре типа ошибок на конкретных примерах.

15) Орфографические ошибки. Орфографические ошибки - это ошибки в правописании слов, т.е. ошибки в написании, неверное написание прописной или строчной буквы, а также недостающие или лишние буквы. В примерах «不要触摸! Не трони!» и 《车未停稳前不 能下车! Не выходить до полной остановке!» допущены ошибки в правописании слов. Не трони следует писать как «не тронь». В словосочетании Не выходить до полной остановке в слове «остановка» также допущена орфографическая ошибка, правильный вариант звучит так: «Не выходить до полной остановки». В примере «不要进

\begin{tabular}{|c|c|c|}
\hline Тип ошибки & \multicolumn{2}{|c|}{ Примеры } \\
\hline \multirow{3}{*}{ 1.0рфографические ошибки } & 不要触摸！ & Не трони! \\
\hline & 不要进入! & Не входит! \\
\hline & 车未停稳前不能下车! & Не выходить до полной остановке! \\
\hline \multirow{3}{*}{ 2.Грамматические ошибки } & $\begin{array}{l}\text { 在滑行、起飞和降落时，显示器和控制手柄必须收 } \\
\text { 起并锁好 }\end{array}$ & $\begin{array}{l}\text { Уложит дисплей и столики при выруливании, взлёте } \\
\text { и посадке }\end{array}$ \\
\hline & 危险，红色警告灯闪亮时严禁开门（客舱已增压） & Запрещается открыть двери при красном свете \\
\hline & 严禁破坏则所烟雾探测器 & Запрещается портить дымосигнализатор в туалете \\
\hline \multirow{2}{*}{ 3.Лексические ошибки } & 勿推货车乘梯 & Запрещается пользоваться лифтом с тележкой \\
\hline & 请留下您的建议 & Запишите мнение! \\
\hline \multirow{3}{*}{ 4.Стилистические ошибки } & $\begin{array}{l}\text { Не бросайте туалетную бумагу и средства личной гигиены } \\
\text { в унитаз }\end{array}$ & 不往马桶内仍卫生纸及个人卫生用品 \\
\hline & Не курить & 别抽烟 \\
\hline & Не входить! Идет государственный экзамен & Не входить! Идет государственный экзамен \\
\hline
\end{tabular}


入! Не входит!» пропущена буква «ь» в конце слова, правильный вариант «Не входить».

16) Грамматические ошибки. К грамматическим ошибкам относят морфологические и синтаксические ошибки, т.е. неверное словообразование или неверный порядок слов. В примере «在滑行、起飞和降落时，显示器 和控制手柄必须收起并锁好Уложит дисплей и столики при выруливании, взлёте и посадке» ошибка заключается в неправильном порядке слов, а также некорректном переводе существительных. В словосочетании «严禁破 坏则所烟雾探测器 Запрещается портить дымосигнализатор в туалете» существительное дымосигнализатор следует переводить как противопожарные датчики, или датчики дыма.

17) Лексические ошибки. Лексические ошибки подразумевают нарушение норм сочетаемости слов, или неправильное использование основного или контекстуального значения слова [14]. Вывеска «勿推货车乘 梯Запрещается пользоваться лифтом с тележкой» может ввести в заблуждение потенциального реципиента, поскольку данная вывеска в китайском варианте отнюдь не запрещает пользование лифтами и тележками, но предупреждает о том, что вход в лифт с тележками запрещен. Вывеска «请留下您的建议 Запишите мнение!» будет звучать более привычно для носителя русского языка, если будет переведена как «Пожалуйста, оставьте ваше мнение».

В нашем исследовании мы также хотели бы рассмотреть еще один вид переводческих ошибок применительно лингвистического ландшафта в комбинации русского и китайского языков - стилистические ошибки.

18) Стилистические ошибки. Для них характерны стилистическая неоднородность, ошибки при переводе фигур речи, употребление словосочетаний неуместных в данном контексте. Перевод данной вывески на китай- ский язык «Не бросайте туалетную бумагу и средства личной гигиены в унитаз 不往 马桶内仍卫生纸及个人卫生 用品》 стилистически неверен, поскольку более характерен для разговорного стиля. В связи с тем, что текст вывесок относится к деловому стилю, более уместным здесь был бы следующий перевод: :请务把卫生纸及个人卫 生用品扔进马桶内. Вариант перевода вывески в следующем примере «Не курить 别抽烟》 также больше характерен для разговорного стиля, более уместным здесь был бы перевод «禁止吸烟》. Пример «Не входить! Идет государственный экзамен不要进入! 正在国考》 также демонстрирует вариант перевода более характерного для разговорного стиля. Для конструкций не + глагол в начальной форме/ + императив правильным был бы перевод 请勿... 禁止... 莫... , соответственно в данном примере корректный перевод звучал бы следующим образом: 《国考进行中，请勿进入》。

\section{Выводы}

Поскольку лингвистический ландшафт также является отражением степени открытости, экономической активности, политической ориентации и т.д., применение лингвистического ландшафта в контексте укрепления российско-китайских отношений становится одной из наиболее актуальных тем для изучения.

Несовершенство лингвистического ландшафта в Китае и России тесно связано с культурными и языковыми различиями между двумя странами. К языковым отличиям мы можем отнести различия в фонетике, лексике, грамматике и стилистике, которые естественным образом сказываются на точности при переводе с китайского языка на русский и с русского языка на китайский.

Таким образом, в целях улучшения лингвистического ландшафта Китая и России наряду с укреплением процесса культурного обмена между двумя этносами, обе страны должны усилить контроль над качеством перевода.

\section{ЛИТЕРАТУРА}

1. Пешкова Н.П. Исследование городского лингвистического ландшафта как способа межкультурного взаимодействия в полиэтническом социуме// Вопросы психолингвистики. 2016. №3. С. 229-238.

2. Landry R., Bourhis R.Y. Linguistic Landscape and Ethnolinguistic Vitality. An Empirical Study // Journal of Language and Social Psychology. 1997. Vol. 16. P. 23-49.

3. Котельникова Н.Н. Лингвокультурные особенности текстов вывесок как фрагмента семиотического пространства современного китайского города // Вестник самарского университета. История, педагогика, филология. 2019. № 3. С. 131 - 138.

4. Вестник Второго Пекинского института иностранных языков. 2016. № 4. 北京第二外国语学院学2016 年第 4 期 (总第 252 期).

5. Кирилина А.В. Описание лингв. Ландшафта как новый метод исследования языка в эпоху глобализации. А.В. Кирилина // Вестник Тверского государственного университета. Серия: Филология. 2013. № 24. Выпуск 5. С. 159 - 167.

6. Лю Лифэнь Русский компонент лингвистического ландшафта Города Санья: современное состояние // Политическая лингвистика. 2017. № 6. С. 184 - 190.

7. Синекопова Г.В. Языковые меньшинства в лингвистическом ландшафте Москвы // Вестник Российского нового университета. Серия: человек в современном мире. 2015. № 2. С. $45-49$.

8. Шан Говен, Чжао Шоухуэй. Теория и метод исследования лингвистического ландшафтов [J]. Преподавание и исследование иностранных языков, 2014(2). C. 214-223. 
9. Пешкова Н.П. Лингвистический ландшафт полиэтнического города. Особенности вербального воздействия // Вопросы психолингвистики. 2017 . № 4. C. $108-118$.

10. Тарасов Е.Ф. Психологические и психолингвистические аспекты речевого воздействия // Речевое воздействие психологические и психолингвистические проблемы. - М.: Институт языкознания АН СССР. 1986. С. 4-9.

11. Комиссаров В.Н. Современное переводоведение. Учебное пособие. / В.Н.Комисаров. - М.: ЭТС. 2001. 424 С.

12. Левый Иржи. Искусство перевода. М.: Издательство «ПРОГРЕСС», 1974. 395 с.

13. Мань Шу Специфика двуязычных китайско-русских вывесок пограничного города Маньчжурия // Вестник Удмуртского университета. Серия «История и филология». 2018. Т. 28. Выпуск 5. С. 820 - 822.

14. Цзюньлин Гу, Чжунлянь Хуан Система классификации переводческих ошибок // Вестник Московского университета. Серия 22. Теория перевода. 2016. № 3. C. $26-40$.

๑ Лю Цзинпэн (liudabao7777@gmail.com).

Журнал «Современная наука: актуальные проблемы теории и практики»

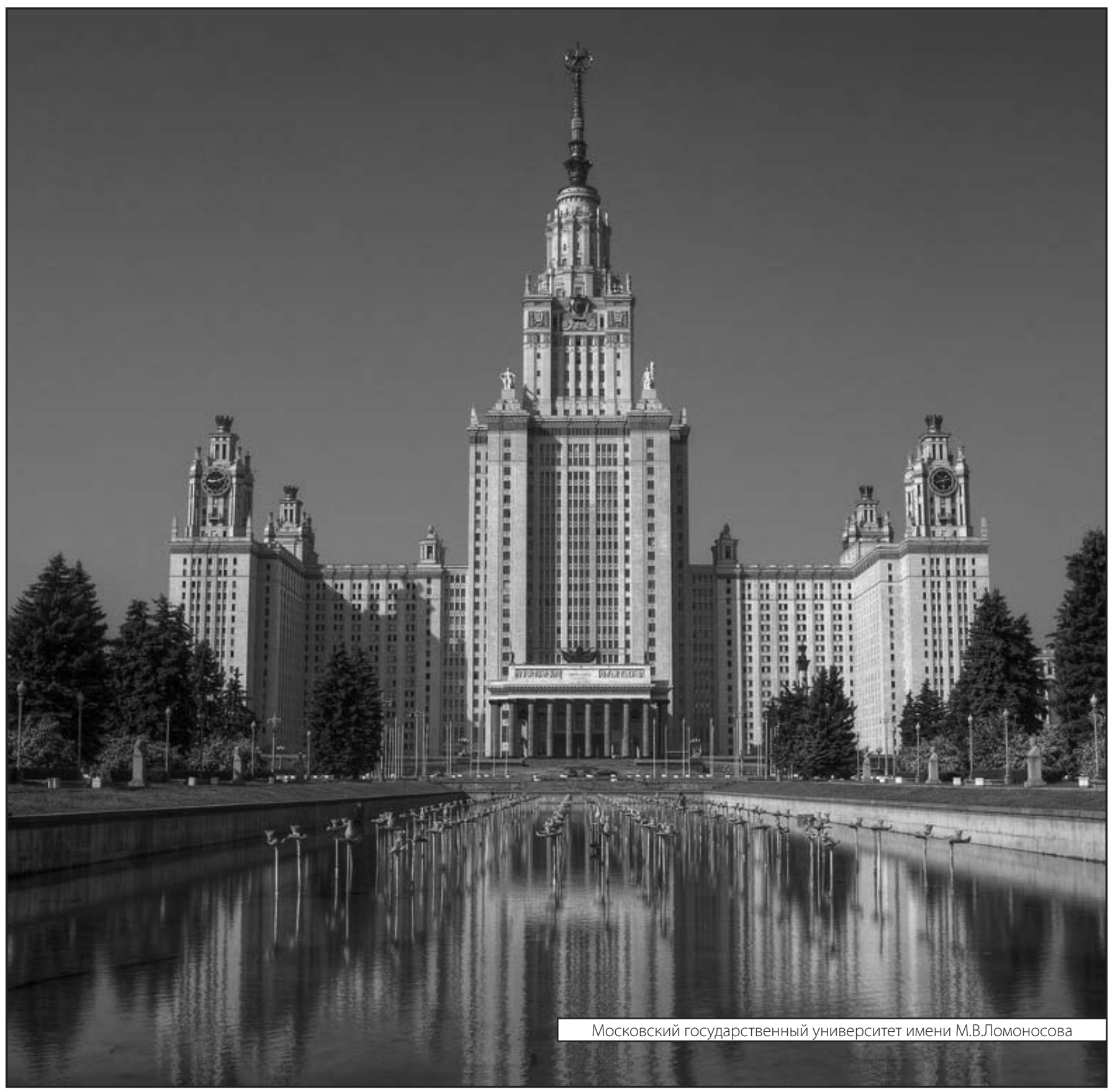

